\section{La exclusión social en los hogares con algún miembro con discapacidad durante el período de crisis en España}

\author{
Social exclusion in households with members \\ with disabilities during the Spanish economic \\ crisis
}

\section{Resumen}

El análisis del impacto que la crisis ha tenido en la discriminación, la pobreza y, especialmente, la exclusión social de las personas y hogares con algún miembro con discapacidad, es el principal objeto de este artículo. Para ello se ha utilizado, como fuente principal, la serie de encuestas realizada por la Fundación FOESSA en los años 2007, 2009 y 20I3. Se observa que el impacto de la crisis no ha sido tan grande en las personas y hogares con discapacidad como en el conjunto de la población de España. Sin embargo, la estabilidad de unos niveles de pobreza y exclusión, que persisten en ser superiores a los registrados en el conjunto de la población, nos informa sobre las limitaciones que las políticas sociales actuales tienen para lograr modificaciones significativas en esta realidad que afecta a los Derechos Humanos de las personas con discapacidad.

\section{Palabras clave}

Discapacidad, exclusión social, España, crisis.

\begin{abstract}
This article analyses the impact that the economic crisis has had on discrimination, poverty and social exclusion among people with disabilities and households with members with disabilities. For this analysis, a series of surveys conducted by the FOESSA Foundation in 2007 , 2009 and 2013 were used. The effect of the economic crisis has not been as great among people with disabilities and households that include members with disabilities as among the overall Spanish population. However, the fact that poverty and exclusion levels among the former group remained higher than those of the overall Spanish population reflects the limitations of current social policies in changing this situation which affects the human rights of people with disabilities.
\end{abstract}

\section{Keywords}

Disability, social exclusion, Spain, economic crisis.

\section{Sagrario Anaut Bravo \\ <sanaut@unavarra.es>}

Universidad Pública de Navarra

\section{Javier Arza Porras}

<javier.arza@unavarra.es>

Universidad Pública de Navarra
Para citar:

Anaut, S. y Arza, J. (20I 5): "La exclusión social en los hogares con algún miembro con discapacidad durante el período de crisis en España”, Revista Española de Discapacidad, 3 (I): 7-28.

Doi: <http://dx.doi.org/IO.5569/23405IO4.03.OI.OI>

Fecha de recepción: I 8-O2-20 I 5 Fecha de aceptación: I3-05-20I 5 


\section{Introducción}

El surgimiento de nuevos modelos de comprensión de la discapacidad ha facilitado el desarrollo de abordajes con un carácter más integral. La consideración de las múltiples dimensiones de un fenómeno de características biopsicosociales, como es el que nos ocupa, ha permitido que el foco deje de estar centrado únicamente en los aspectos biologicistas y asistenciales. Así, conceptos como derechos humanos, ciudadanía, inclusión social o participación social, cada vez están más presentes en el ámbito discursivo de la discapacidad.

En este artículo se ha abordado específicamente la relación entre la discapacidad y la exclusión social, un concepto vinculado a estos nuevos modelos de comprensión holística de la discapacidad. La exclusión social es un fenómeno multidimensional diferenciado del tradicional concepto de pobreza. Si la pobreza se suele asociar únicamente a la falta de recursos económicos, el concepto de exclusión implica la consideración de otras muchas variables: educación, salud, vivienda, vínculos familiares y sociales, empleo, etc. En ese sentido, la exclusión social supone una acumulación de carencias en todas (o casi todas) esas variables, implicando la ruptura del vínculo social, la privación de derechos sociales y, en definitiva, la desigualdad.

Para dimensionar el alcance de la exclusión social en los hogares con algún miembro con discapacidad se han explotado las tres encuestas sobre integración social y necesidades sociales de la Fundación FOESSA (2007, 2009 y 2013). De ellas también se ha obtenido información sobre la pobreza en esos hogares y en las personas con discapacidad. Para completar la visión de lo que supone la exclusión social se ha introducido un apartado dedicado a la experiencia de la discriminación a partir de la Encuesta 3000 del CIS.

Con la mirada puesta en el análisis longitudinal, el artículo se adentra en la tendencia de los impactos de la exclusión social durante la crisis en los hogares sin y con algún miembro con discapacidad. De sus comportamientos se podrá deducir si la brecha entre ambas modalidades de hogares se acrecienta o no.

\section{Inclusión social, derechos humanos y discapacidad}

El estudio de la discapacidad en España ha estado condicionado por la disponibilidad de fuentes de información estadística (Puga y Abellán, 2004:7; Huete y Quezada, 20I2). Hasta la Encuesta sobre discapacidades, deficiencias y minusvalias (I986) y, sobre todo, desde la Encuesta sobre discapacidad, deficiencias y estado de salud (EDDES) de I999, la mayoría de los estudios publicados se centraron en propuestas de intervención sobre algún tipo de discapacidad (Béland y Zunzunegui, I995; Barton, I998), en políticas o estrategias socio-sanitarias (Verdugo et al., I994; IMSERSO, I997) y en colectivos concretos (Bermejo et al., 2002). Esta situación cambiará con la disponibilidad de los datos de la EDDES y la aprobación de la segunda Clasificación del funcionamiento, de la discapacidad y de la salud por la OMS en 200I. Trabajos como los de Abellán (2000), Verdugo (2000), Palacios (2006, 2008), Seelman (2004), Querejeta (2004) o De Lorenzo y Pérez Bueno (2007) apuntan hacia nuevos modelos y enfoques de la discapacidad, una mayor precisión conceptual y cuantitativa de la realidad de la discapacidad, así como hacia los retos de una sociedad posmoderna.

El creciente interés por la inclusión social de las personas con discapacidad ha abierto interrogantes sobre el cómo lograrla, a partir de qué y de quién, hacia dónde, con qué medios propios y colectivos. El desafío para la sociedad se ha traducido en el desarrollo de políticas sociales con capacidad para atender las diferentes dimensiones de la discapacidad. En este sentido el enfoque basado en los derechos humanos se presenta como un cambio en la 
mirada social y personal. El Informe Mundial sobre la Discapacidad de la OMS (20II: 9-II) insiste en que la discapacidad es una cuestión de derechos humanos, por cuanto las personas con discapacidad experimentan situaciones de desigualdad y de violación de la dignidad, en ocasiones, por prejuicios y abusos, y tienen serias dificultades para lograr su autonomía personal.

Con este enfoque de recuperación de derechos se han publicado estudios, como los Informes para España sobre Derechos Humanos y Discapacidad, elaborados por CERMI desde 2008. Otros trabajos, como los de Etxebarría (2008) y Díaz (2010) avanzaban en su reflexión hacia el concepto de ciudadanía de las personas con discapacidad, señalando la necesidad de considerar la participación de estas personas en su vida, no sólo en aspectos asistenciales, sino en los sociales y políticos. Recientemente, Alonso (20II), Martínez Ríos (20I I y 20I3) o Raya et al. (20I2 y 20I3), coinciden en mostrar la necesidad de un cambio de enfoque y paradigma hacia los derechos humanos, sin el cual no se podrá superar la situación recogida en el Informe de la ONU citado.

Sobre la idea de los derechos humanos se apoya el modelo social de tratamiento de la discapacidad (Raya y Caparrós, 20I3: I9I-I98). Este modelo se ha ido introduciendo, desde la década de los sesenta del siglo XX, hasta alcanzar hoy un alto nivel de consenso en la producción científica en cuanto a su definición y a las implicaciones que tiene en materia de políticas socio-sanitarias, de intervención y de desarrollo de un tejido comunitario más inclusivo. En paralelo, han irrumpido discursos renovados como los que consideran la discapacidad una condición humana, de modo que ninguna persona cuenta con todas las capacidades que demanda la sociedad o el entorno (Anaut et al, 20I2). También aquellos otros que promueven una visión holística e integradora (biopsicosocial) de las situaciones de discapacidad (De Lorenzo y Pérez Bueno, 2007).

Así como se ha evolucionado hacia una concepción social del constructo "discapacidad"
(Anaut et al., 20I 2: 27-34), hay autores que avanzan hacia una definición social de la ciudadanía, en concreto, de ciudadanía multicultural, de ciudadanía diversa. Muchas de las entidades del ámbito de la discapacidad sensorial y el Movimiento de Vida Independiente (Palacios y Romañach, 2006: 34-35) han reivindicado este posicionamiento en el que las personas con discapacidad presentan una diversidad más a las del resto de personas (diversidad funcional). El reconocimiento de una mayor diversidad requiere que el contexto/ entorno elabore o re-elabore respuestas que garanticen la igualdad de oportunidades. Las instituciones públicas, en este punto, han de garantizar el completo ejercicio de la ciudadanía. Este enfoque implica una actuación no sólo reactiva que remueva las barreras a la participación, sino una línea de trabajo promocional que impulse las medidas necesarias para ofrecer oportunidades a las personas en función de sus necesidades.

La relación entre el modelo social y los derechos humanos queda plasmada, igualmente, en la legislación de España, especialmente desde la aprobación de la Convención de la ONU sobre los derechos de las personas con discapacidad, como reflejan en sus trabajos el Colectivo Ioé (20I2) y Marbán (20I3). Se ha avanzado en la defensa de los derechos de las personas con discapacidad y su inclusión social, por ejemplo, con la Ley 26/20I I y el Real Decreto Legislativo $\mathrm{I} / 20 \mathrm{I} 3^{\mathrm{I}}$. Asimismo, se ha seguido la recomendación de la Convención de la ONU y de la Estrategia Europea sobre Discapacidad, 2010-2020 (2010), para elaborar y activar la Estrategia Española sobre Discapacidad (20I22020). En ella destacan como obstáculos a la adaptación del entorno a las personas con discapacidad: la insuficiencia y las limitaciones de las políticas y normas, sobre todo, en cuanto a su eficacia; las actitudes sociales negativas; una financiación insuficiente; la falta de

I. Ley 26/20I I, de I de agosto, de adaptación normativa a la Convención Internacional sobre los Derechos de las Personas con Discapacidad; Real Decreto Legislativo I/2013, de 29 de noviembre, por el que se aprueba el Texto Refundido de la Ley General de derechos de las personas con discapacidad y de su inclusión social. 
participación de las personas con discapacidad; los obstáculos a la información; y la limitación en la accesibilidad.

Ciertamente, todos estos pasos dados hasta la fecha suponen un salto cualitativo en el desarrollo de un modelo de derechos humanos en materia de discapacidad. Pero la realidad cotidiana no siempre se ajusta a la construcción conceptual y legal. Trabajos como el de Huete (20I3b: 2I) resaltan una cierta mejoría en materia de sensibilización y concienciación de la sociedad sobre la discapacidad. Sin embargo, los datos de la Encuesta Social Europea (2010)2, que él maneja, muestran la persistencia de la situación de invisibilización de la población con discapacidad y la consiguiente experiencia de la discriminación y la exclusión social. En las siguientes páginas se procederá al análisis de la realidad de la discapacidad a partir de las encuestas sobre integración social y necesidades sociales (EINSFOESSA) para constatar si se han producido esos mismos avances que apuntarían a la reducción de la situación de exclusión y pobreza de las personas y los hogares con algún miembro con discapacidad.

\section{La discapacidad en la encuesta sobre integración social y necesidades sociales de la Fundación FOESSA (EINSFOESSA)}

Trabajos recientes como los de Rodríguez Álvarez (2013: 75-94), Huete (20I2: I66-I67) o Raya Díez (2012: 47-72) identifican y analizan distintas bases de datos que recogen información cuantitativa sobre la discapacidad en la sociedad. Además de las encuestas específicas sobre discapacidad del INE de los años I986, I999 y 2008, es posible acceder a otras más genéricas como la Encuesta de Condiciones de Vida (ECV) y la Encuesta de Población Activa

2. Es un estudio comparado y longitudinal que se lleva a cabo cada dos años, en el que participan alrededor de 30 países europeos. Trata de analizar la evolución en actitudes y comportamientos de la población europea. Cuenta con una muestra de personas con discapacidad.
(EPA). Sus datos facilitan comparar la situación en la que se encuentran las personas con y sin discapacidad. En este segundo grupo de encuestas se encuentran las EINSFOESSA.

Hasta la fecha se han realizado tres EINSFOESSA (2007, 2009 y 2013), cuyo objetivo central ha sido cuantificar las condiciones de vida y la exclusión social en España. A partir de sus datos, se ha procedido a la medición de la exclusión social con la aplicación de un sistema de 35 indicadores que recogen las principales dimensiones de la exclusión: empleo, consumo, participación política, educación, vivienda, salud, conflicto social y aislamiento social. Con la suma ponderada de todos esos indicadores se obtiene el denominado Índice Sintético de Exclusión Social (ISES). A partir de ahí, y de acuerdo con la incidencia de los diferentes indicadores de exclusión en cada uno de los hogares y personas encuestados, han quedado distribuidos en cuatro grupos: integración, exclusión precaria, exclusión moderada y exclusión severa (Trujillo, 20I4: 667-668). Para poder comparar los resultados de las tres encuestas se ha utilizado el sistema de ponderación de los indicadores correspondiente al año 2007.

Por su parte, la medición de la pobreza ha seguido un enfoque metodológico estándar en la Unión Europea: línea de la pobreza relativa. Se ha calculado "sobre la base de la variable monetaria de los ingresos y teniendo en cuenta las unidades de consumo del hogar y las escalas de equivalencia” (Trujillo, 20I4: 669).

En cuanto al procedimiento seguido, ha sido muy similar en las tres encuestas. Como unidad de encuestación se han tomado los hogares. El muestreo ha sido bietápico: selección de secciones censales y selección mediante rutas aleatorias. Ello ha facilitado el acceso a suficientes hogares en situación de exclusión social. El tamaño muestral final en 2013 fue de 8.769 cuestionarios de hogares. 
Tabla 1: Cuantificación del universo, muestra y margen de la EINSFOESSA de 2013

\begin{tabular}{|l|c|}
\hline Universo, muestra, margen & Cuantificación \\
\hline Universo población & 47.129 .783 \\
\hline Universo hogares & 17.440 .800 \\
\hline Muestra población & 24.775 \\
\hline Muestra hogares & 8.776 \\
\hline Margen de error población & $+0,6$ \\
\hline Margen de error hogares & $+1,0$ \\
\hline Número de Municipios & 530 \\
\hline
\end{tabular}

Fuente: Trujillo (2014: 665).

Para facilitar la obtención de la muestra necesaria se elaboraron dos cuestionarios (filtro y completo) que se pasaron en dos fases. En la primera, se contactó con los hogares y se pasó el cuestionario filtro. Con la información recogida se clasificó a cada hogar en: hogar con indicios de exclusión y hogar sin indicios. De la muestra total, 6.073 correspondieron a los primeros hogares y 2.696 a los segundos.

En la segunda fase se pasó el cuestionario extenso, compuesto por 99 preguntas codificadas. Estas preguntas se agrupan en ocho bloques de extensión muy variada. Los dos bloques más extensos (más de veinte preguntas cada uno) tratan la situación económica y la percepción de la situación en la que se encuentran los hogares en España. El resto de bloques recogen datos básicos de los hogares y sus miembros, el nivel de estudios y formación, el estado de salud, autovalimiento y necesidades específicas, el empleo, la vivienda y los servicios sociales.

La discapacidad aparece recogida en el bloque dedicado al estado de salud, autovalimiento y necesidades específicas. En la explotación de las dos primeras encuestas (2007 y 2009) se detectó que la pregunta referida a la detección de casos con discapacidad era imprecisa: "¿Alguna persona del hogar padece alguna minusvalía, enfermedad crónica o problemas graves de salud que le genere limitaciones para realizar las actividades diarias?”. Para solventar esta cuestión se introdujo en el cuestionario de $20 \mathrm{I} 3$ una pregunta previa más concisa: “¿Alguna persona del hogar padece alguna minusvalía/ discapacidad?". Este cambio ha producido una reducción del número de hogares con algún miembro con discapacidad respecto a las dos encuestas anteriores. Una leve distorsión que también pudo detectarse en sentido contrario en la encuesta de 2009 , entonces como efecto de la extensión de los reconocimientos de la situación de dependencia y no siempre la diferenciación entre discapacidad y dependencia por parte de las personas entrevistadas.

\section{Discapacidad y pobreza}

Las personas con discapacidad, y los hogares en los que viven, alcanzan niveles de pobreza más elevados. Ahora bien, la discapacidad no es sinónimo de pobreza, sino un factor más de riesgo. Trabajos como los de Pérez Bueno y Huete (2008) o de Anaut et al. (2010) demostraron que esta realidad se mantenía en el tiempo al margen de la bonanza o crisis económica, si bien detectaron que las políticas dirigidas a un apoyo más intensivo sobre los hogares que tenían algún miembro con discapacidad amortiguaban la intensidad de la pobreza. Es decir, permanece la tradicional interrelación discapacidad-pobreza de carácter bidireccional, pero con matices en función de la intensidad y diversidad de las políticas públicas y del nivel de impacto de las crisis.

Para entender la relación bidireccional del binomio discapacidad-pobreza, Martínez Ríos (2013: I 2-22) realiza una revisión de diferentes propuestas teóricas que han contribuido a que la discapacidad sea tenida en cuenta como un aspecto importante para lograr un avance económico general. Desde ahí, concluye la autora, puede establecerse un patrón común en el que la discapacidad se caracteriza por suponer un mayor coste de vida, dependiendo ese coste de la naturaleza y nivel de severidad de la discapacidad, así como de las barreras 
actitudinales, sociales y físicas (Martínez Ríos, 2OI3: 25).

Otras aproximaciones focalizan su interés en el impacto de la crisis actual sobre el empleo y la pobreza, analizando por tanto los ingresos de los hogares con algún miembro con discapacidad (Anaut et al., 2010: 225-235). Huete (2013b: I4), por ejemplo, ha calculado que los niveles medios de ingresos en los hogares donde vive alguna persona con discapacidad son inferiores a los de aquellos sin miembro con discapacidad, según la Encuesta Social Europea de 20 Io.

Estas diferencias se acrecientan en los niveles de ingresos más bajos: el 35,8 1 \% de la población con discapacidad vive en hogares con ingresos iguales o inferiores a 900 euros, frente al $20,48 \%$ en la población general. Asimismo, el 36, I $4 \%$ de la población con discapacidad reconoce dificultades para llegar a fin de mes, frente al I9,I3 \% de la población general.

Marbán et al. (201 2: 57) introduce ciertas concreciones al tratar la incidencia de la pobreza a partir de los datos de la EDAD 2008. El hecho de que la tasa de pobreza de las personas con discapacidad sea "casi el doble que la del resto de la población” se entiende que es efecto de la estructura demográfica de este colectivo caracterizado por su envejecimiento y feminización. De esta forma, la modalidad de ingreso que predomina en los hogares con personas con discapacidad son las pensiones contributivas $(75 \%$, frente al $39 \%$ de promedio en el resto de hogares). En cuanto a la feminización, Huete (2013 a: 39) estima que el riesgo de pobreza afectaba por igual a mujeres y varones con discapacidad en 2008 , si bien se detectaban diferencias en cuanto a la situación de pobreza extrema ( $17,3 \%$ de las mujeres y i I \% de los varones) y de carencia de prestaciones $(47 \%$ de mujeres y $40 \%$ de varones en 2OII).

Otros autores (Whitehead y Dahlgren, 2006; Benach y Muntaner, 20I0; OMS, 20II) se han centrado más en la influencia de los determinantes sociales en la salud. Sostienen que la vinculación entre pobreza y discapacidad se explica por diferentes factores complementarios: el tener los hogares pobres mayor riesgo de padecer enfermedades y accidentes; mayores dificultades de los hogares pobres para financiar determinados tratamientos de rehabilitación; y el empobrecimiento que puede ocasionar la discapacidad por las dificultades de inserción laboral, las limitaciones de las pensiones y los gastos extra en fármacos, tratamientos y apoyos técnicos.

Con el mismo trasfondo que pone en evidencia la relación entre discapacidad y pobreza, se expresa el Informe de Cruz Roja sobre vulnerabilidad social (Malgesini, 20I3: I3-I 5). En él, se reitera el peso del ámbito económico en esta situación y se destaca la progresiva homogeneización del mapa que identifica los diversos perfiles de vulnerabilidad.

La última EINSFOESSA (2013) ha facilitado disponer de una serie breve de encuestas sobre la situación de pobreza por colectivos. Como se recoge en el siguiente gráfico, la crisis económico-financiera ha seguido agravando los niveles de pobreza de las personas sin discapacidad ( $19,4 \%$ en 2009 y $28,7 \%$ en 20I3), en tanto se han estabilizado los de las personas con discapacidad (en torno al $25 \%$ ) entre 2009 y 2013 . Al mismo tiempo, la situación de las personas con discapacidad, con y sin certificado de discapacidad, ha tendido a igualarse. Ambos procesos adquieren un carácter claramente novedoso que requiere un análisis.

Estas tendencias pueden explicarse, aunque parcialmente, por la representación de las personas en situación de dependencia reconocida entre quienes dicen tener discapacidad (40,6\%) y por el incremento en la muestra de las personas con discapacidad y certificados de reconocimiento de la misma (2007: 60\%; 2009: $53 \%$; y 20I3: $80 \%$ ). Por tanto y coincidiendo con Belzunegui et al. (2OI4: 54), todo apunta a que ciertos mecanismos y prestaciones de protección que se han ido implantando, como las transferencias públicas vinculadas al reconocimiento de la situación de dependencia (Ley 39/2006) y/o las dedicadas a la discapacidad, o como la aplicación de la Estrategia global para el empleo de las personas 

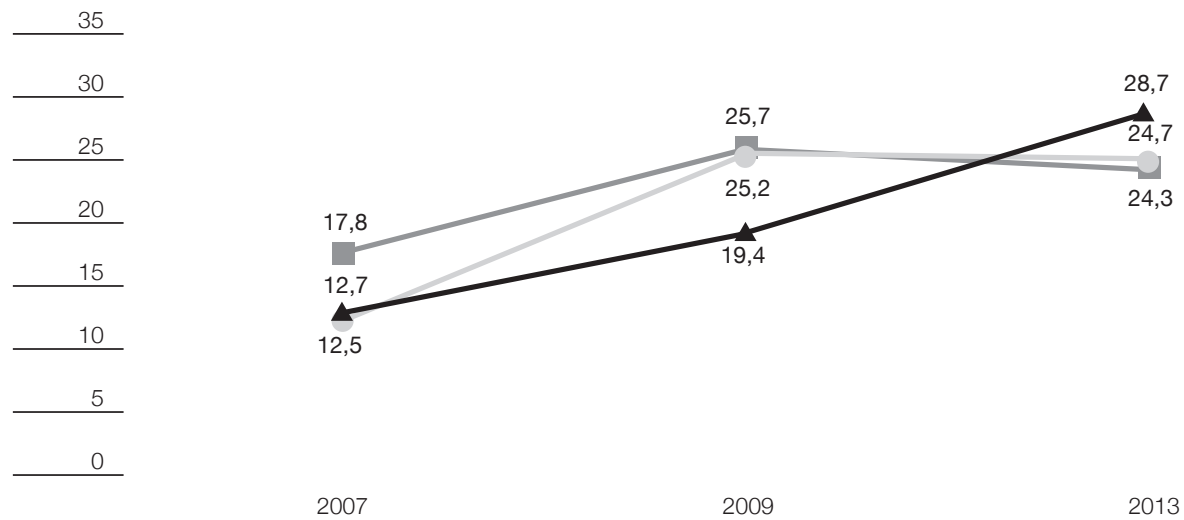

Sin discapacidad

Con discapacidad

Con discapacidad + Certificado

Fuente: EINSFOESSA 2007, 2009 y 2013.

con discapacidad (2008-I2), han estado amortiguando, que no reduciendo, la intensidad del creciente impacto de la situación de crisis actual.

El carácter multidimensional de la pobreza también requiere adentrarse en matices sobre su intensidad. La pobreza severa entre las personas con discapacidad se ha mantenido en niveles idénticos entre 2007 y $2013(4,7 \%)$, mientras que en el conjunto de la población ha aumentado del $3,5 \%$ al $7,3 \%$. La pobreza moderada, en cambio, se ha incrementado en más de seis puntos entre las personas con discapacidad ( $13 \%$ en 2007 y I9,6\% en 2013 ) 3 . Es decir, el empobrecimiento se produce por la entrada en esta situación de quienes no eran pobres. Este hecho pudo constatarse ya en la EINSFOESSA de 2009. En ese momento se produjo un desplazamiento hacia la pobreza moderada, tanto desde las situaciones de no

3. El Informe Olivenza 20I4 establece que la pobreza severa afecta al $14,7 \%$ de las personas con discapacidad y que la pobreza moderada lo hace al $32 \%$ (Observatorio Nacional de la Discapacidad, 2015:46I) pobreza como de pobreza severa, dando como resultado un crecimiento global de la pobreza en las personas con discapacidad (del I 7,8 \% en 2007 al 25,7\% en 2009).

En 2013, la situación experimenta cambios mínimos respecto al año 2009, detectándose una ligera reducción global de la pobreza ( I,4 puntos), aunque aún se mantiene una diferencia de seis puntos y medio respecto al porcentaje de pobreza registrado antes de la crisis. En comparación con el conjunto de la población, la pobreza entre las personas con discapacidad sigue siendo elevada, a pesar del importante crecimiento experimentado en la pobreza del conjunto de la población española desde el inicio de la crisis.

Estos datos vuelven a llamar la atención sobre las limitaciones de las prestaciones sociales, incluso las asociadas a los reconocimientos de dependencia y/o discapacidad, a la hora de paliar las situaciones más graves. No obstante, han ejercido su función paliativa desde el momento en que ha descendido el peso de las 
personas con discapacidad en situación de pobreza severa respecto del total de personas encuestadas: $7,7 \%$ en $2007,8,7 \%$ en 2009 y 4,6\% en 20I3. Asimismo, han evitado mantener una progresión ascendente de los casos de pobreza moderada: $7,9 \%$ en 2007 , I I, $5 \%$ en 2009 y $6,8 \%$ en 2013 .

Coincide este resultado con la afirmación de Ayala (20I4: 43) para el conjunto de la sociedad, según la cual los aumentos de la pobreza durante períodos de crisis solo pueden evitarse con una elevada inversión en recursos sociales. En el caso que nos ocupa ha habido más recursos garantizados de los sistemas de protección social destinados a las personas con discapacidad y con una situación de dependencia que para la población sin discapacidad, y eso a pesar de los recortes. Ahora bien, estos recursos han sido insuficientes para reducir el elevado nivel de pobreza de las personas con discapacidad y para modificar la tendencia más allá de la estabilización.

Por su parte, la pobreza en los hogares con algún miembro con discapacidad ha seguido la misma tendencia descrita a título individual, si bien con una mayor representación de la incidencia de la pobreza respecto al conjunto de hogares. Así, en 2013, los hogares con alguna persona con discapacidad que se encontraban en situación de pobreza moderada eran el I 8,3 \% del conjunto de hogares en esa misma situación, y el I $4, \mathrm{I} \%$ entre los hogares en pobreza severa, en tanto las personas con discapacidad representaban el $6,8 \%$ y $4,6 \%$, respectivamente, del conjunto de personas encuestadas.

Se confirma que la pobreza creció en los hogares con alguna persona con discapacidad y, sobre todo, el impacto fue importante entre $2007 \mathrm{y}$ 2009. Se observa, en cambio, una suave mejoría entre 2009 y $20 \mathrm{I}_{3}$, que se traduce en el paso del $27,7 \%$ de hogares con algún miembro con discapacidad en situación de pobreza en 2009 al 24,I \% en 20I3, básicamente, por la salida de la pobreza moderada (del $24,2 \%$ en 2009 al I9,7\% en 2013).

A su vez, las diferencias entre disponer o no de un certificado de discapacidad apenas son visibles, excepto en 2007. Cabía esperar que disponer de un certificado podía evitar las situaciones de pobreza severa, pero no

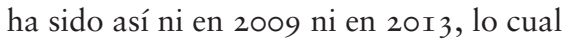
pone en cuestión la efectividad real de este reconocimiento que posibilita el acceso a más prestaciones.

Gráfico 2. Porcentajes de niveles de pobreza de hogares con algún miembro con discapacidad (total) y aquellos que además cuentan con un certificado de discapacidad (2007, 2009 y 2013)
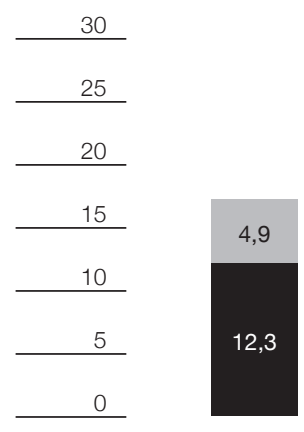

Total

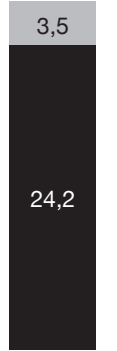

Total

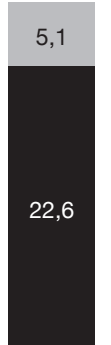

Certificado 2009

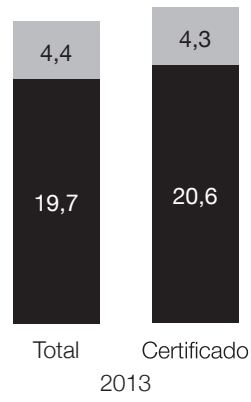

Pobreza moderada

Pobreza severa

Fuente: EINSFOESSA 2007, 2009 y 2013. 
En suma, las personas con discapacidad y los hogares en los que residen siguen manteniendo altos niveles de pobreza, sobre todo moderada. Ciertamente, no ha empeorado tanto su situación en los últimos años de la crisis como la de quienes no tienen discapacidad, pero este hecho no puede ocultar que la incidencia de la pobreza sigue siendo muy alta.

Es decir, la situación de estabilidad de la pobreza individual presentada entre 2009 y $20 \mathrm{I}_{3}$, a pesar de la profundización de la crisis, resulta un tanto engañosa. Quizá solo supone dar un respiro y reconocer la capacidad paliativa de las políticas sociales.

Otras aproximaciones realizadas al tema, como las de Huete (2013b: I3), corroboran esta conclusión, si bien lo hacen tomando como indicador el riesgo de pobreza de la población con discapacidad (el 48,4\% se halla por encima de los límites de riesgo de pobreza). En todo caso, parece cierto que se reproduce, al igual que sucede entre las personas que perciben una pensión contributiva, el hecho de una mejoría de la posición relativa de quienes tienen una discapacidad y de los hogares con algún miembro con discapacidad por la estabilidad en la percepción de ciertas prestaciones.

5. La exclusión social: el espejismo de la estabilidad

A partir de los datos de la Encuesta Social Europea, Huete afirma que las personas con discapacidad sufren un situación de exclusión "en el ámbito educativo y alcanzan inferiores niveles de estudios que el resto de la población; disponen de menos oportunidades para acceder al mercado de trabajo; hacen frente a restricciones extraordinarias para participar activamente en la sociedad, y desarrollar una vida afectiva y social normalizada" (2OI3b: 2I). A conclusiones similares llegan, entre otros, los trabajos de Huete (20I3a), Colectivo Ioé (20I2) y Anaut et al. (2010).
Durante el período analizado a través de las tres EINSFOESSA, no se observan cambios muy significativos en las situaciones de exclusiónintegración que afectan a las personas con discapacidad. Comparando el año 2013, respecto al periodo anterior a la crisis, se observa un incremento de casi ocho puntos en las situaciones de integración precaria. Este incremento se ha producido por el desplazamiento desde la exclusión moderada hacia la integración precaria ( 5 , I puntos), pero también desde la integración plena a la integración precaria (3,7 puntos). Asimismo, se ha detectado que la exclusión severa se ha incrementado en un punto. En suma, aunque se han producido algunos pequeños transvases porcentuales entre los cuatro tipos de integración-exclusión, la crisis no ha incrementado el espacio social de la exclusión de las personas con discapacidad $(33 \%$ en 2007 y $29 \%$ en 2013 ).

Esta imagen puede completarse comparando la situación de las personas con discapacidad respecto a la del conjunto de la población española. Si en el periodo anterior a la crisis la incidencia de la exclusión era prácticamente I7 puntos superior en las personas con discapacidad, en el año 2013 se ha reducido la distancia a cinco puntos. Esta tendencia a la aproximación en los porcentajes de exclusión se ha producido fundamentalmente por el espectacular aumento de la misma en el conjunto de la población, y no tanto porque haya mejorado significativamente la situación entre las personas con discapacidad.

La situación descrita puede hacerse extensible en sus grandes rasgos a la de los hogares. Se observa un incremento de 4,6 puntos en el porcentaje de hogares en integración precaria, así como una subida de un punto en las situaciones de exclusión severa (gráfico 6). Estos datos reiteran que la crisis no ha incrementado el impacto de la exclusión en los hogares donde habita alguna persona con discapacidad (29,6\% en el año 2007 y $28 \%$ en el año 20I3).

La comparación con los hogares de la población general nos indica una tendencia a 
la aproximación en los porcentajes de hogares excluidos. Si en el año 2007 el porcentaje de hogares excluidos en los que habitaba alguna persona con discapacidad era I4 puntos superior en comparación con el conjunto de la población, en el año $20 I_{3}$ la diferencia se reduce a 6,I puntos. También en este caso la aproximación se produce por la agudización de las situaciones de exclusión de la población en su conjunto.

Gráfico 3. Evolución de los niveles de integración social en el conjunto de hogares y en los hogares con alguna persona con discapacidad (2007-2013)

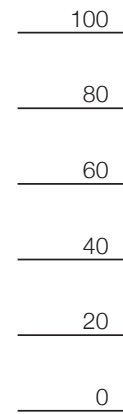

0
2007

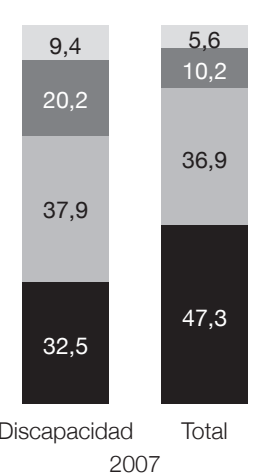

Integrado

Integración precaria

Exclusión moderada

Exclusión severa

Fuente: EINSFOESSA 2007, 2009 y 2013.
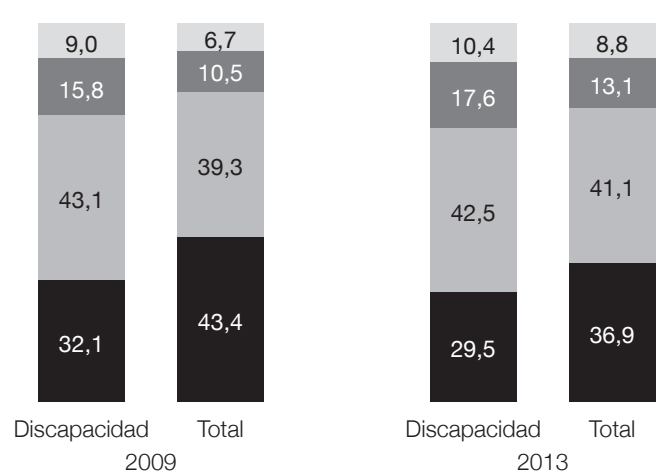

Discapacidad Total 2013

\section{Gráfico 4. Evolución de los niveles de integración-exclusión en los hogares con alguna persona con} discapacidad que cuenta con certificado de discapacidad (2007-2013)

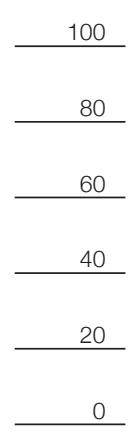

Integrado

Integración precaria

Exclusión moderada

Exclusión severa

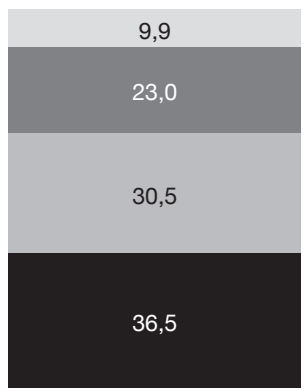

2007

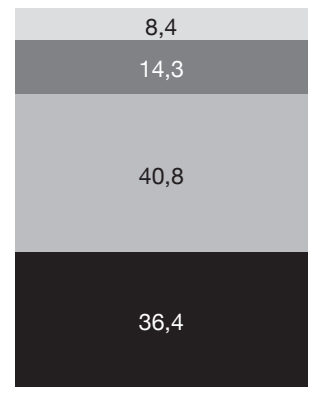

2009

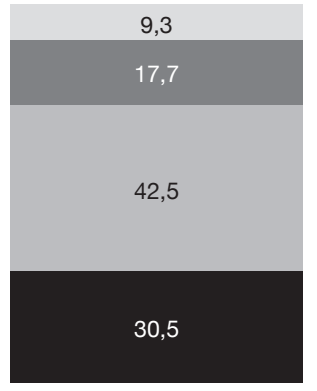

2013

Fuente: EINSFOESSA 2007, 2009 y 2013. 
Disponer de certificado de discapacidad, como se ha apuntado en el apartado dedicado a la situación de pobreza, no impide que un hogar se encuentre en situación de exclusión. En el siguiente gráfico se comprueba la evolución de estos hogares entre el año 2007 y el 20I3. En ese periodo se observó una mejoría al desplazarse algunos hogares ( Io puntos de diferencia) del espacio de la exclusión social al de la integración precaria. Sin embargo, entre el año 2009 y el 2013 vuelve a aumentar en cuatro puntos el espacio de la exclusión (tanto moderada como severa) y se reduce en seis el de la integración. Gráfico 7. Evolución de los niveles de integración-exclusión en los hogares con alguna persona con discapacidad que cuenta con certificado de discapacidad (2007-2013)

En conclusión, el empeoramiento en la situación de las personas con discapacidad y de los hogares con algún miembro con discapacidad no es tan acusado como en el caso de la población general. Siendo más estable su situación, la tendencia descrita durante los años de crisis es hacia la reducción de la integración, al tiempo que se incrementan ligeramente las situaciones de exclusión severa y, sobre todo, de integración precaria.

\section{Las dimensiones de la exclusión social}

La evolución seguida por las diferentes dimensiones de la exclusión en los hogares con algún miembro con discapacidad dibuja trayectorias diversas en los tres momentos en que se han elaborado las EINSFOESSA. Si comparamos la situación del año 20I3, respecto a la recogida en el periodo anterior a la crisis (2007), podemos observar cierta estabilidad en las dimensiones de empleo, educación, vivienda y aislamiento social, mientras que se reduce la exclusión en consumo y salud, y se incrementa en la exclusión política y en conflicto social. Los mayores porcentajes de exclusión, respecto al conjunto de los hogares, se observan en salud, educación y conflicto social. Así, uno de cada tres hogares en situación de exclusión en salud tiene alguna persona con discapacidad, prácticamente lo mismo en el caso de la exclusión en educación y uno de cada cuatro en el caso del conflicto social.

Tabla 2. Porcentaje de hogares con algún miembro con discapacidad respecto del total de hogares según la dimensión de exclusión social (2007-2013)

\begin{tabular}{|l|c|c|c|}
\hline & $\mathbf{2 0 0 7}$ & $\mathbf{2 0 0 9}$ & $\mathbf{2 0 1 3}$ \\
\hline Exclusión del empleo & 12,6 & 19 & 16,2 \\
\hline $\begin{array}{l}\text { Exclusión del } \\
\text { consumo }\end{array}$ & 22,6 & 21,7 & 15,9 \\
\hline Exclusión política & 6,3 & 11,3 & 13,4 \\
\hline $\begin{array}{l}\text { Exclusión de la } \\
\text { educación }\end{array}$ & 28,7 & 31,5 & 29,6 \\
\hline $\begin{array}{l}\text { Exclusión de la } \\
\text { vivienda }\end{array}$ & 19,6 & 21,6 & 19,3 \\
\hline Exclusión de la salud & 41,7 & 54,8 & 34,9 \\
\hline Conflicto social & 17 & 27,9 & 24,9 \\
\hline Aislamiento social & 13,5 & 15,7 & 15 \\
\hline
\end{tabular}

Fuente: Elaboración propia a partir de EINSFOESSA 2007, 2009 y 2013.

Por otro lado, las diferentes dimensiones de la exclusión han afectado de forma diversa a las situaciones de integración precaria, exclusión moderada y exclusión severa en 2013 (gráfico 5). La exclusión en educación, vivienda, salud y empleo, por ese orden, son las dimensiones más presentes en los hogares precarios con algún miembro con discapacidad. En los hogares en exclusión moderada, los mayores déficits se concentran en las dimensiones de política, aislamiento social, conflicto social y salud. Los conflictos sociales, el aislamiento, la vivienda $\mathrm{y}$, especialmente, los problemas de consumo, sobresalen en aquellos hogares afectados por la exclusión severa.

Hay que destacar, por tanto, que los déficits o problemas ligados al propio engranaje de los sistemas de protección social se convierten en factores desencadenantes de la pérdida de 
integración de los hogares con alguna persona con discapacidad. Estos ámbitos pierden protagonismo en las dos situaciones de exclusión (moderada y severa), cuando las dificultades en la dimensión política, los conflictos sociales y el aislamiento social adquieren mayor protagonismo. Es también aquí y, sobre todo, en la exclusión severa, donde se hace visible la problemática del consumo (dificultades para acceder a bienes considerados básicos y la pobreza extrema).

El análisis de las tres EINSFOESSA permite concluir que la dimensión educativa ha experimentado cierta mejoría en algunos aspectos, como el porcentaje de hogares con alguna persona analfabeta mayor de 65 años ( $16,4 \%$ de los hogares con algún miembro con discapacidad en 2007 y 9,4\% en 2013 ), o con alguna persona de I 6 a 64 años sin completar estudios $(6,7 \%$ en 2009 y $4,4 \%$ en 2013$)$. No obstante, sigue siendo preocupante que, entre los hogares con una formación mínima, siga habiendo una alta representación de hogares que tienen alguna persona con discapacidad (uno de cada cuatro hogares en los que hay alguna persona de I 6 a 64 años que no tiene estudios).
La vivienda, así como su entorno, forma parte de los derechos sociales básicos y, en el caso de la discapacidad, determina de manera muy relevante las posibilidades de participación social. Los indicadores referidos a la vivienda de la última EINSFOESSA muestran un empeoramiento de los hogares con algún miembro con discapacidad, aunque se haya reducido el hacinamiento $(6,8 \%$ en 2007 y $3,6 \%$ en $\left.20 \mathrm{I}_{3}\right)$ y la tenencia en precario de la vivienda ( $4 \%$ en 2007 y I, $3 \%$ en 2013 ).

Se ha detectado un incremento en el porcentaje de hogares que declaran un entorno muy degradado (0,6\% en 2007 y 2,I \% en $20 \mathrm{I} 3$ ) y barreras arquitectónicas en el hogar $(4,8 \%$ en 2009 y $6,8 \%$ en 20I3). También es preocupante que un porcentaje significativo de hogares declare tener problemas de insalubridad, humedades, suciedad, olores, etc., en sus viviendas ( I I,7\% en 20I3). Asimismo, se ha incrementado el porcentaje de hogares que tienen que hacer un esfuerzo de gasto excesivo en vivienda $(6, \mathrm{I} \%$ en 2007 y 9, I \% en $20 \mathrm{I} 3)$, lo que puede redundar en su empobrecimiento y en las dificultades para acometer mejoras necesarias en sus viviendas.

Gráfico 5. Hogares con algún miembro con discapacidad, afectados por las dimensiones de la exclusión social en 2013 (\% respecto de la dimensión de exclusión)

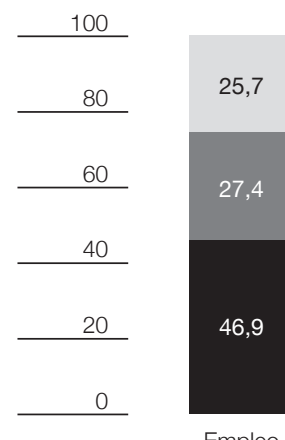

Empleo
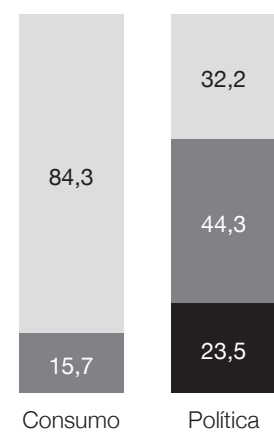

Política

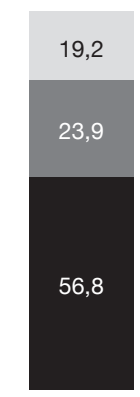

Educación

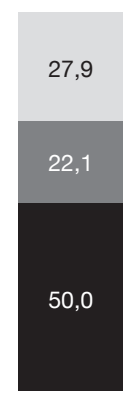

Vivienda

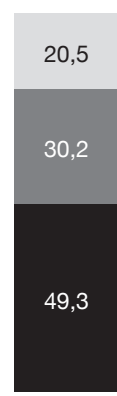

Salud

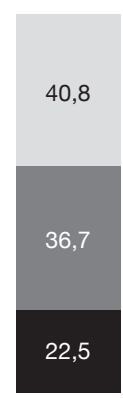

Conflicto

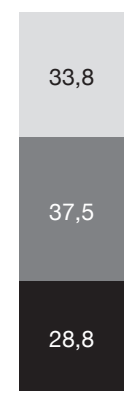

Aislamiento

Integración precaria

Exclusión moderada

Exclusión severa

Fuente: EINSFOESSA 2013. 
Los hogares en los que vive alguna persona con discapacidad están especialmente representados entre los hogares que sufren situaciones de exclusión en salud. Aunque ha disminuido el porcentaje de hogares con todas las personas adultas padeciendo problemas graves de salud y limitación de la actividad diaria (I 6,9\% en 2007 y I $4,7 \%$ en 2013 ) se trata de un conjunto de hogares con necesidades múltiples y complejas. Especialmente preocupantes son los casos que declaran haber pasado hambre en los últimos io años (de 3,2 \% en 2007 a 4,6\% en 2013 ), que no compran medicinas, ni siguen tratamientos/ dietas por problemas económicos (de 9,9\% en 2007 a I $8,6 \%$ en 20I3), o que tienen alguna persona dependiente y no reciben apoyo $(6,6 \%$ en 2007 a $7, \mathrm{I} \%$ en 2013 ).

Se observa, por último, una importante presencia de estos hogares entre aquellos que sufren situaciones de conflicto familiar. Así, según la EINSFOESSA de 20I3, uno de cada tres hogares que declaran tener malas relaciones en la familia tiene alguna persona con discapacidad. La sobrecarga que sufren muchas de estas familias, que en ocasiones no cuentan con los suficientes apoyos sociales, puede estar detrás de una mayor presencia de conflictos familiares.

\subsection{Indicadores económicos de la exclusión social}

Los datos aportados por el INE (2013: I), sobre el empleo de las personas de I 6 a 64 años, permite visualizar la enorme brecha que separa a las personas con y sin discapacidad en este ámbito. $\mathrm{El}$ 36,6\% de las personas con discapacidad reconocida era considerada población activa en $20 \mathrm{I} 2$, frente al $77 \%$ de la población sin discapacidad. Su tasa de empleo era del $24,5 \%$, es decir, más de 30 puntos de diferencia con respecto a las personas sin discapacidad. En cuanto a la tasa de paro de las personas con discapacidad era 8 puntos superior.

Los datos obtenidos a través de las encuestas EINSFOESSA confirman que la tasa de actividad en las personas de I 6 a 64 años

Tabla 3. Tasas de actividad, empleo y paro de las
personas con y sin discapacidad entre 16 y 64
años (2009 y 2012)
\begin{tabular}{|l|c|c|c|c|}
\hline & \multicolumn{2}{|c}{ Con } \\
discapacidad & discapacidad \\
\cline { 2 - 5 } & $\mathbf{2 0 0 9}$ & $\mathbf{2 0 1 2}$ & $\mathbf{2 0 0 9}$ & $\mathbf{2 0 1 2}$ \\
\hline Tasa de actividad & 36,2 & 36,6 & 75,4 & 77 \\
\hline Tasa de empleo & 28,3 & 24,5 & 61,8 & 57,8 \\
\hline Tasa de paro & 21,8 & 33,1 & 18,1 & 25 \\
\hline
\end{tabular}

Fuente: INE (20I3: 5).

con discapacidad se ha situado en torno al 3 I \% durante el periodo analizado. Entre la población activa con discapacidad afirman estar trabajando en torno al $62 \%$ en las dos últimas encuestas. Esto supone un porcentaje del $20 \%$ respecto del total de personas con discapacidad de I 6 a 64 años en el año 2013 .

Disponer de un empleo, como se ha reiterado en los últimos años, no es sinónimo de integración social plena. En el siguiente gráfico se constata esta afirmación ya que, aunque la mayor parte de las personas con empleo se sitúan en el espacio de la integración (plena o precaria), también existe un porcentaje de en torno al $20 \%$ que se encuentran en 2013 en el espacio social de la exclusión (moderada o severa). Además, el análisis de la evolución experimentada desde el año 2007 indica que se ha producido una tendencia hacia el incremento de la integración precaria y, más levemente, de la exclusión moderada.

A pesar de la tendencia al empeoramiento en la situación de las personas con discapacidad que trabajan, son estas personas y quienes perciben alguna pensión o se dedican a labores del hogar las que se encuentran en un mayor nivel de integración en el año 2013. No obstante, el porcentaje de precariedad en la integración es superior al $40 \%$ en los tres casos. Las personas que buscan empleo son las que se encuentran en una situación más difícil. Prácticamente el $58 \%$ se sitúan en el campo de la exclusión (moderada o severa). 
Gráfico 6. Distribución porcentual en los espacios de integración/exclusión de las personas con discapacidad que trabajan $(2007,2009$ y 2013)

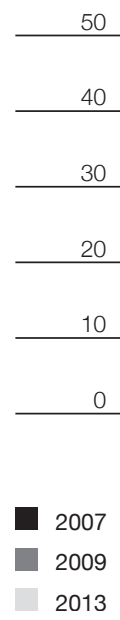

Fuente: EINSFOESSA 2007, 2009 y 2013.

Tabla 4. Distribución porcentual en los espacios de integración/exclusión según la ocupación de las personas con discapacidad mayores de 16 años (2013)

\begin{tabular}{|l|c|c|c|c|}
\hline & Integrado & $\begin{array}{c}\text { Integración } \\
\text { precaria }\end{array}$ & $\begin{array}{c}\text { Exclusión } \\
\text { moderada }\end{array}$ & Exclusión severa \\
\hline Trabajando & 34,7 & 43,7 & 16,6 & 5 \\
\hline Buscando empleo & 3,5 & 38,6 & 28,9 & 28,9 \\
\hline Estudiante & 55 & 35 & 5 & 5 \\
\hline $\begin{array}{l}\text { Percibía alguna pensión/ } \\
\text { ingresos prejubilación }\end{array}$ & 26,7 & 46,3 & 18,9 & 8 \\
\hline Labores del hogar & 31,1 & 42,2 & 18 & 8,7 \\
\hline Otras & 33,9 & 36,1 & 13,1 & 16,9 \\
\hline
\end{tabular}

Fuente: EINSFFOESSA 2013.

En el proceso de búsqueda de empleo, un elemento a tener en cuenta es la inscripción en los servicios públicos de empleo. Resulta reseñable el elevado porcentaje de personas con discapacidad que no se inscriben en este tipo de servicios. Según las EINSFOESSA, entre el año 2007 y el 20I3, únicamente el $20 \%$ de las personas de 16 a 64 años con discapacidad estaban inscritas. Hipotéticamente, podríamos vincular este dato con la pérdida de expectativas de muchas personas con discapacidad respecto a la posibilidad de encontrar un empleo, y especialmente respecto a poder encontrarlo a través de ese tipo de servicios.

Respecto a los hogares en los que alguna persona tiene discapacidad, se registran algunos indicadores de exclusión en la dimensión de empleo e ingresos económicos (tabla 5). Especialmente destacables son los porcentajes 
Tabla 5. Incidencia de los indicadores del eje económico de exclusión social en los hogares con algún miembro con discapacidad

\begin{tabular}{|l|c|c|c|}
\hline Participación en la producción & $\mathbf{2 0 0 7}$ & $\mathbf{2 0 0 9}$ & $\mathbf{2 0 1 3}$ \\
\hline Sustentador principal 12 meses o más parado & 3,5 & 5,6 & 5,9 \\
\hline Sustentador principal con un oficio de exclusión & 0,8 & 1,7 & 1,4 \\
\hline Hogares con sustentador principal sin cobertura de la seguridad social & 0,6 & 1,1 & 1,2 \\
\hline Hogares sin ocupados, sin pensiones ni prestaciones contributivas & 8,8 & s.d. & 8,5 \\
\hline Hogares con algún parado y sin formación ocupacional & 8,2 & 23,2 & 23,9 \\
\hline Todos los activos en paro & 5,9 & 13,9 & 12,3 \\
\hline Participación del producto social & $\mathbf{2 0 0 7}$ & $\mathbf{2 0 0 9}$ & $\mathbf{2 0 1 3}$ \\
\hline Pobreza extrema & 4,9 & 3,5 & 4,4 \\
\hline Carece de bienes básicos & s.d. & s.d. & 2 \\
\hline
\end{tabular}

Fuente: EINSFFOESSA 2007, 2009 y 2013.

al alza en hogares con alguna persona desempleada y sin formación ocupacional $(8,2 \%$ en 2007 y $23,9 \%$ en 2013$)$, con todas las personas activas en paro $(5,9 \%$ en 2007 y I 2,3\% en 20I3) y en los que el sustentador principal lleva I 2 meses o más parado $(3,5 \%$ en 2007 y $5,9 \%$ en 2013).

En comparación con el conjunto de hogares, la representación de los hogares con algún miembro con discapacidad es especialmente relevante (uno de cada cinco hogares en el año 20I3) en aquellos que tienen carencia de bienes básicos, en los que todas las personas activas están en paro y en los que no tienen a nadie ocupado, con pensión o prestación contributiva.

7. La experiencia de la discriminación en el ámbito de la discapacidad

El Eurobarómetro sobre discriminación (European Commission, 20I2) muestra que la discapacidad es el segundo motivo de discriminación percibido por la ciudadanía en el conjunto de la Unión Europea (46\%), y también en el Estado Español (40\%), donde hay síntomas de mejoría en la sensibilización (Huete, 20I3b: 2I). Asimismo, es considerada uno de los principales obstáculos en el acceso al empleo. Para el $38 \%$ de las personas encuestadas en España, y el $40 \%$ en la Unión Europea, la discapacidad es una desventaja "cuando una empresa quiere contratar a alguien y puede elegir entre dos candidaturas con las mismas habilidades y cualidades" (European Commission, 20I2).

En la más reciente encuesta realizada por el CIS sobre discriminación (CIS, 20I3), también se observa que la discriminación por discapacidad se sitúa en los primeros puestos en cuanto a la percepción que la ciudadanía tiene sobre su extensión, y con unos porcentajes aún superiores a los obtenidos en el Eurobarómetro. Destaca especialmente la "discapacidad psíquica", que ocupa el segundo lugar con casi un $59 \%$ de personas que consideran muy o bastante frecuente la discriminación por este motivo (únicamente superada por la discriminación por origen étnico o racial). En cuanto a la “discapacidad física”, el porcentaje se sitúa casi en el $50 \%$. 


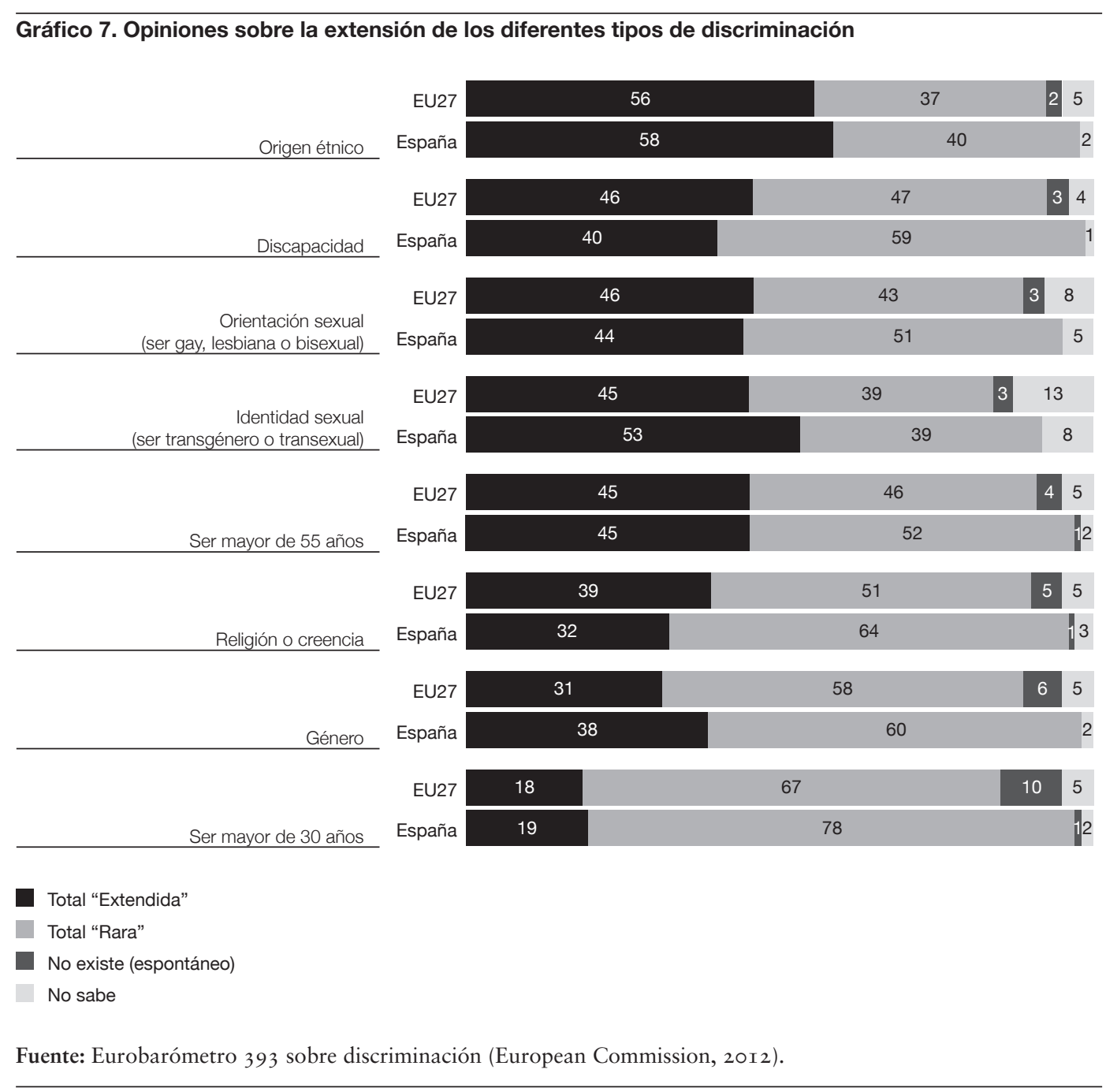

Esta importante incidencia en la percepción de discriminación por discapacidad, parece no corresponderse con una alta presencia en la sociedad de actitudes de rechazo hacia las personas con discapacidad. En la encuesta ya mencionada sobre discriminación (CIS, 20I3), apenas se detectan personas que declaren sentirse molestas ante la vecindad de una persona con discapacidad física (el 95,6\% señalan la opción "nada”). En el caso de la discapacidad intelectual, aunque el porcentaje de personas que indican la opción "nada" sigue siendo mayoritario $(84,7 \%)$, también se detecta un pequeño grupo al que les molestaría "algo", "bastante" o "mucho" la vecindad de estas personas ( $8 \%$ en total). No obstante, también debemos señalar que las preguntas incorporadas en el cuestionario quizás no sean suficientes para detectar uno de los tipos de actitudes propiciatorias de la discriminación en el caso de la discapacidad, como son las vinculadas al paternalismo o la desconfianza en las capacidades de estas personas (Arza, 20I4: I34-I37).

Se observa también falta de correspondencia entre la alta percepción respecto a la presencia en la sociedad de la discriminación por discapacidad y el relativamente bajo porcentaje de personas que declaran sufrirla. Así, la 
Gráfico 8. Proporción de población que cree que la discriminación es muy o bastante frecuente en cada tipo

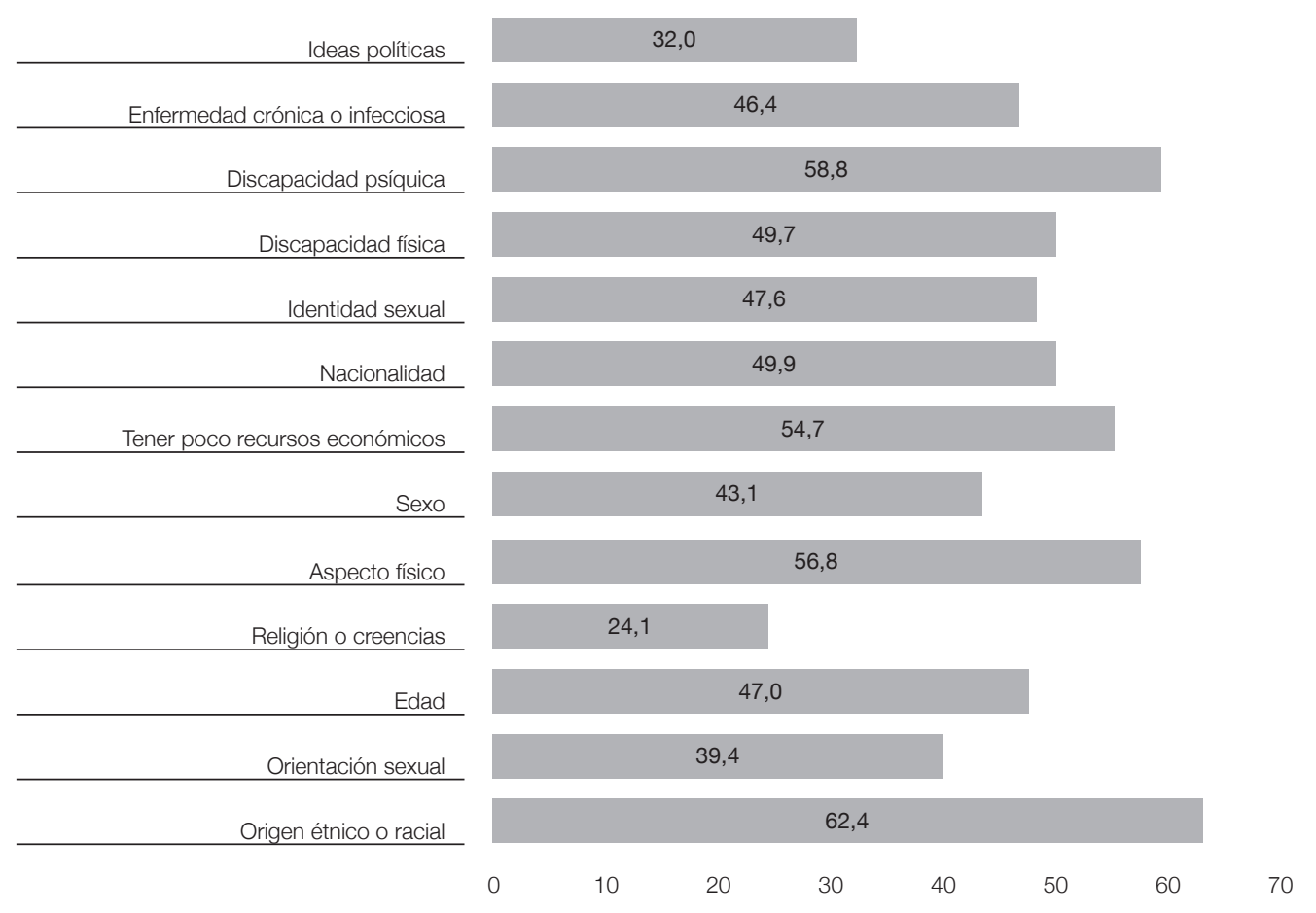

Fuente: Elaboración propia a partir de encuesta 3000 sobre discriminación (CIS, 20I3).

encuesta EDAD (INE, 2008) señala que el I $2 \%$ de las personas con discapacidad se han sentido discriminadas por ello, mientras que el $88 \%$ declaran no haberse sentido así nunca.

En el caso de la encuesta 3000 sobre discriminación (CIS, 20I3), no se puede establecer el porcentaje de personas con discapacidad que se han sentido discriminadas, ya que no se planteó ninguna pregunta que permitiera identificar a las personas con discapacidad. No obstante, disponemos de un dato: el porcentaje de personas que en los últimos doce meses ha sido testigo (ha visto $\mathrm{u}$ oído) alguna discriminación por discapacidad sufrida por alguna persona cercana: $8,4 \%$. Como podemos observar, y como venimos insistiendo, el porcentaje dista mucho de la percepción sobre la presencia de la discriminación por discapacidad en nuestra sociedad.
En una publicación del CERMI (Jiménez y Huete, 2003: 24) se establece una diferenciación entre dos tipos de discriminación. La primera es la que sufre directamente la persona con discapacidad, que en muchos casos está vinculada con aspectos socio-relacionales y tiene como consecuencia que se sienta infravalorada, menospreciada, invisibilizada, temida, etc., en su relación con otras personas. La segunda es un tipo de discriminación de tipo contextual y podemos vincularla con los conceptos de accesibilidad y diseño para todas las personas. Estos conceptos plantean que todos aquellos entornos y productos que no estén diseñados para permitir la participación, el acceso, el uso, a todo tipo de personas, son entornos y productos discriminatorios.

Puede considerarse, a modo de hipótesis, que el primer tipo de discriminación es más fácil de 
detectar, mientras que el segundo requiere un mayor nivel de concienciación, por lo que es más difícil que pueda ser detectado en este tipo de encuestas. De hecho, desde una concepción tradicional de la discapacidad, cuando una persona tiene dificultades para acceder a un entorno o usar un producto, se tiende a pensar que el problema está en la "falta de capacidad" de la persona. Sin embargo, los conceptos de accesibilidad y diseño para todas las personas plantean que el problema está en que los entornos y los productos, al ser diseñados pensando en un supuesto patrón medio de persona, son discriminatorios e incapacitantes. Vinculando esta reflexión con el estudio de la discriminación, y para lograr incrementar la capacidad de detección de las encuestas, sería necesario incorporar preguntas que faciliten a la persona la vinculación de este tipo de situaciones contextuales con la discriminación por discapacidad (Arza, 20I4: I34-I37).

En relación con el perfil de la persona con discapacidad que se ha sentido discriminada, debemos acudir de nuevo a la encuesta EDAD (INE, 2008). En ella se plantea que el perfil es el de un varón, menor de 65 años, desempleado y con "deficiencias mentales o del sistema nervioso". Respecto a los ámbitos o situaciones en las que ha sufrido la discriminación, destaca especialmente el de las relaciones sociales, seguido de la participación social y el acceso a la atención sanitaria. Finalmente, en la práctica totalidad de los casos $(92,3 \%)$ no denunciaron la situación de discriminación sufrida. Este escaso porcentaje de situaciones denunciadas, además de responder al desconocimiento, falta de canales de denuncia o insuficiente información que las personas afectadas tienen sobre los procedimientos que se deben seguir, también puede estar relacionado con la necesidad de incrementar la conciencia en este colectivo respecto a sus derechos de ciudadanía (Arza, 20I4: I34-I37).

\section{Reflexiones finales}

Han trascurrido casi cuatro años desde la anterior EINSFFOESSA (2009). Desde entonces la crisis económica se ha agudizado hasta límites impensables. La nueva fotografía que traslada la EINSFFOESSA (2013) no es alentadora en términos generales. Entre sus conclusiones destaca la socialización de la exclusión social. En este marco, las personas con discapacidad y los hogares en los que residen no parecen haberse visto tan duramente golpeados, lo que no encubre su situación de desventaja endémica.

El colectivo de personas con discapacidad ha descendido en un punto entre 2009 y $20{ }_{3}$ (del $8,2 \%$ al $7,3 \%$ ), cuando se esperaba un cierto repunte como efecto del sobre-envejecimiento de la población. Mantiene, en cambio, la sobrerepresentación de las personas mayores de 65 años (por encima del $40 \%$ ), la feminización ( $5 \mathrm{I} \%$ ) y los bajos niveles de estudios $(50 \%$ alcanza niveles de ESO y superiores) y ocupación ( $52 \%$ son pensionistas y I $2 \%$ empleados). Esta estabilidad del perfil de las personas con discapacidad corre paralela a la recogida en materia de discriminación, pobreza y exclusión social. La rigidez al cambio en un contexto de fuertes desajustes solo puede entenderse desde la comprensión de una apariencia epidérmica o bien de las dificultades para detectar cambios en el corto plazo cuando el empeoramiento más intenso ya se había producido (2007-2009).

Ciertamente, al analizar en las tres EINSFFOESSA la evolución de la situación de las personas con discapacidad y los hogares en los que viven, se han observado variaciones en cuanto al impacto de la exclusión social en la discapacidad. Así, se ha recogido el estancamiento de la pobreza relativa, pero en niveles altos. Además, queda constatada una leve reducción de la integración, a costa del incremento en la integración precaria y de un pequeño aumento de la exclusión severa, aunque teniendo en cuenta que se parte de una importante extensión de la exclusión. Muy distinto ha sido el impacto entre quienes 
no tienen una discapacidad, ya que se ha incrementado notablemente la pobreza relativa y la exclusión social en muy pocos años.

Si bien los datos indican que disponer de un certificado de discapacidad no ha sido suficiente para reducir los niveles de pobreza y exclusión alcanzados en 2009, su generalización entre los hogares encuestados puede explicar que no hayan repuntado más. Lo mismo podría decirse de la percepción de una pensión o de un empleo protegido. Es decir, el mantenimiento, en unos casos, y el refuerzo, en otros, de prestaciones sociales han demostrado su capacidad para prevenir el deterioro de la situación social e incluso el agravamiento de la precariedad social. Este efecto protector que el sistema les podía aportar ha sido reconocido por las personas con discapacidad y sus hogares de modo que se ha incrementado, de manera notable, el porcentaje de personas con certificado de discapacidad.

Sin embargo, parece claro también que el sistema de prestaciones técnicas, materiales y económicas tiene importantes limitaciones en cuanto a su capacidad para modificar, realmente, los desequilibrios, la falta de accesibilidad, de los diferentes entornos en los que se desenvuelven las personas con discapacidad y sus hogares.

En términos comparativos, en suma, los efectos de la crisis en los últimos cuatro años han sido menos dramáticos entre quienes tenían una discapacidad reconocida que entre quienes no la tenían. Es decir, se perciben ritmos distintos entre unos sectores de población y otros, pero no puede perderse de vista que las diferentes dimensiones de la exclusión social han seguido empeorando entre quienes tienen una discapacidad. 
Referencias bibliográficas

Abellán, A. (2000): "Nuevo modelo del funcionamiento y de la discapacidad". Revista Multidimensional de Gerontología, 3: I89-I92.

Alonso, Ma. J. y De Araoz, I. (20I I): El impacto de la Convención Internacional sobre los Derechos de las personas con discapacidad en la legislación educativa española, Madrid: CERMI, Ediciones Cinca. Colección Convención ONU, n ${ }^{\circ} 6$.

Anaut-Bravo, S. et al. (2010): "El impacto de la crisis económica sobre los hogares con personas con discapacidad”, en Laparra, M. et al. El primer impacto de la crisis en la cohesión social en España (Vol. 32), Madrid: Fundación FOESSA-Cáritas Española.

Anaut-Bravo, S. et al. (20I2): "Discapacidad: modelos y discursos hacia un enfoque de Derechos Humanos“, en Raya, E. et al.: Atención social a personas con discapacidad. Hacia un enfoque de Derechos Humanos, Buenos Aires: Lumen-Humanitas.

Arza, J. (20I4): "La discriminación por discapacidad”. En Laparra, M. et al. Estudio sobre percepción de la discriminación en España. Ministerio de Sanidad, Servicios Sociales e Igualdad: Madrid.

Ayala, L. (20I4): “Desigualdad y pobreza en España en el largo plazo: la continuidad de un modelo", en VII Informe FOESSA, Documento de Trabajo 2.I, Madrid: Fundación FOESSACáritas.

Barton, L. (I998): Discapacidad y sociedad, Madrid: Ediciones Morata, Fundación Paideia.

Béland, F. y Zunzunegui, M.V. (I995): “La salud y las incapacidades funcionales. Elaboración de un modelo causal”. Revista de Gerontología, 5: 232-244.

Belzunegui, A. et al. (2OI4): "Discapacidad y pobreza en España en el periodo 2006-20II. El impacto de las transferencias sociales". Sistema. Revista de Ciencias Sociales.
Benach, J. y Muntaner, C. (coords.) (2010): Empleo, trabajo y desigualdades en salud. Una visión global, Barcelona: Icaria.

Bermejo, Ma . L. et al. (2002): "El aprendizaje de las ciencias en niños ciegos y deficientes visuales". Integración: Revista sobre ceguera y deficiencia visual, 38: 25-34.

CIS (2013). Encuesta 3000. Percepción de la discriminación en España (en línea). http:// www.cis.es/cis/export/sites/default/-Archivos/ Marginales/3000_3019/3000/es3000mar.pdf,, acceso de ro febrero de 2015.

Colectivo Ioé (20I2): Discapacidades e inclusión social, Barcelona: Obra Social "La Caixa", Colección Estudios Sociales, $\mathrm{n}^{\circ} .33$.

Comisión sobre Determinantes Sociales en la Salud (CSDH) (2008): Closing the gap in a generation. Health equity through action on the social determinants of health, Ginebra: Organización Mundial de la Salud.

De Lorenzo, R. y Pérez Bueno L. C. (dir.) (2007): Tratado sobre Discapacidad, Pamplona: Thomson Reuters-Aranzadi.

Díaz, E. (20I0): “Ciudadanía, identidad y exclusión social de las personas con discapacidad". Politica y Sociedad, vol. 47 (I)

Esteban, R. y Gutiérrez, D. (20I4): “La incentivación del empleo de las personas con discapacidad en el medio ordinario de trabajo". Revista Española de Discapacidad, 2 (I): 7-32.

Etxebarría, X. (2008): La condición de ciudadanía de las personas con discapacidad intelectual, Bilbao: Universidad de Deusto.

España. Ley 26/20I I, de I de agosto, de adaptación normativa a la Convención Internacional sobre los Derechos de las Personas con Discapacidad, Boletín Oficial del Estado, núm. I 84, de 2 de agosto de 20 I I, pp. 87478 a 87494 .

España. Ley 39/2006, de I4 de diciembre, de Promoción de la Autonomía Personal y Atención 
a las personas en situación de dependencia, Boletín Oficial del Estado, núm. 299, de I 5 de diciembre de 2006, pp. 44I42 a 44I56.

España. Real Decreto Legislativo I/20I3, de 29 de noviembre, por el que se aprueba el Texto Refundido de la Ley General de derechos de las personas con discapacidad y de su inclusión social, Boletín Oficial del Estado, núm. 289, de 3 de diciembre de 2013, pp. 95635 a 95673 .

European Commission (2012). Discrimination in the EU. EBS 393. http://ec.europa.eu/public_ opinion/archives/ebs/ebs_393_en.pdf, acceso de 10 febrero de 2015.

Huete, A. (20I3b): "La exclusión de la población con discapacidad en España. Estudio específico a partir de la Encuesta Social Europea”. Revista Española de Discapacidad, I (2): 7-24.

Huete, A. (20I3a): Pobreza y exclusión social de las mujeres con discapacidad en España, Madrid: Ediciones Cinca-CERMI.

Huete, A. y Quezada, M. (20I 2): La discapacidad en las fuentes estadísticas oficiales. Examen y propuestas de mejora. Análisis formal y de contenido sobre discapacidad en las referencias del Instituto Nacional de Estadística (INE). Madrid: Ediciones Cinca-CINCA.

IMSERSO (I997): La discapacidad en el siglo XXI. Plan de acción. Una propuesta de futuro, Madrid: IMSERSO.

INE (2OI4): El salario de las personas con discapacidad. Explotación de la Encuesta Anual de Estructura Salarial y de la BEPD, Notas de Prensa, 5 de junio de 20I4, Madrid: INE.

INE (2013): El empleo de las personas con discapacidad. Explotación de la EPA y de la $B E P D$, Notas de Prensa, 9 de diciembre de 20I3, Madrid: INE.

Jiménez, A. y Huete, A. (2003): La discriminación por motivos de discapacidad. Madrid: CERMI.

Jiménez, A. y Huete, A. (20I0): "Estadísticas y otros registros sobre discapacidad en España”. Sociedad y Política, vol. 47 (I).

Malgesini, G. (coor.) (20I3): Informe de la vulnerabilidad social 2OII-2OI2, Madrid: Cruz Roja Española.
INE (2008). Encuesta sobre discapacidades, autonomía personal y situaciones de dependencia. EDAD 2008 (en línea). http:// www.ine.es/jaxi/menu.do?type=pcaxis\&path= $\%_{2} \mathrm{Ft}_{\text {I }} \% \%_{2} \mathrm{Fp}_{4}$ I $8 \&$ file=inebase, acceso de ı febrero de 2015 .

Marbán, V. et al. (20I2): El sector de la discapacidad: realidad, necesidades y retos futuros. Análisis de la situación de la población con discapacidad y de las entidades del movimiento asociativo y aproximación a sus retos y necesidades en el horizonte de 2020 , Madrid: Ediciones Cinca-CERMI, Fundación ONCE. Col. CERMI, n ${ }^{\circ} 59$.

Martínez, J. L. (2005): Exclusión social y discapacidad, Madrid: Fundación Promi, Universidad Pontificia de Comillas.

Martínez, B. (20I3): "Pobreza, discapacidad y derechos humanos”. Revista Española de Discapacidad, I (I): 9-32.

Martínez, B. (20I I): Pobreza, discapacidad y derechos humanos. Aproximación a los costes extraordinarios de la discapacidad y su contribución a la pobreza desde un enfoque basado en los derechos humanos, Madrid: CERMI, Ediciones Cinca. Col. Convención ONU, $n^{\circ} 4$.

Medina, J. A. et al. (2012): "Trabajadores pobres y empobrecimiento en España”. Zerbitzuan: Gizarte zerbitzuetarako aldizkaria/Revista de servicios sociales, 52: II9-I 28.

Observatorio Estatal de la discapacidad (2OI 5 ): Informe Olivenza 20I4, sobre la situación de la discapacidad en España. Madrid: Ministerio de Sanidad, CERMI.

Organización Mundial de la Salud (20II): World Report on Disability, Ginebra: OMS-Banco Mundial.

Palacios, A. (2008), El modelo social de discapacidad. Orígenes, caracterización y plasmación en la Convención Internacional sobre los Derechos de las Personas con Discapacidad, Madrid: Cinca.

Palacios, A. y Romañach, J. (2006): El modelo de la diversidad. La Bioética y los Derechos 
Humanos como herramientas para alcanzar la plena dignidad en la diversidad funcional, Santiago de Compostela: Ediciones DiversitasAIES.

Panadero, S. y Pérez-Lozao, M. (20I4): "Personas sin hogar y discapacidad”. Revista Española de Discapacidad, 2 (2): 7-26.

Puga, Ma D. y Abellán, A. (2004): El proceso de discapacidad. Un análisis de la Encuesta sobre discapacidad, deficiencias y estado de salud, Alcobendas: Fundación Pzifer.

Querejeta, M (2004): Discapacidad/dependencia. Unificación de criterios de valoración y evaluación, Madrid: IMSERSO.

Raya, E. et al. (201 2): Atención social a personas con discapacidad. Hacia un enfoque de Derechos Humanos, Buenos Aires: LumenHumanitas.

Raya, E. y Caparrós, N. (20I3): "Derechos Humanos y discapacidad: estrategias de empoderamiento", en Vega, A. $\mathrm{M}^{\mathrm{a}}$ (coor.): Derechos Humanos: Elementos para un nuevo marco conceptual, Pamplona: Thomson Reuters-Aranzadi.
Rodríguez, V. (20I3): "Fuentes de información sobre discapacidad y empleo en España”. Revista Española de Discapacidad, I (I): 73-95.

Seelman, C. C. (2004): “Tendencia en la Rehabilitación y en la Discapacidad: Transición desde un Modelo Médico a un Modelo de Integración”. Disabiliy Word, vol. 22.

Trujillo, M. (20I4): "Diseño muestral de la Encuesta sobre integración social y necesidades sociales", en VII Informe FOESSA, Documento de Trabajo 3.Io, Madrid: Fundación FOESSACáritas.

Verdugo, M. A. et al. (1994): Actitudes hacia las personas con minusvalia, Madrid: Ministerio de Asuntos Sociales, Instituto Nacional de Servicios Sociales.

VERDUGO, M. A. (edt.) (2000): Familias y discapacidad intelectual, Madrid: Colección FEAPS, $\mathrm{n}^{\circ} 2$.

Whitehead, M. y Dahlgren, G. (2006): Concepts and principles for tackling social inequities in health, Copenhage: World Health Organization. 